\title{
Sample Weight
}

National Cancer Institute

\section{Source}

National Cancer Institute. Sample Weight. NCI Thesaurus. Code C87555.

A positive numeric adjustment for a value based on its relative representation in a population. It is used to adjust sample data to correct for design features such as oversampling and design deficiencies such as nonresponse. 